\title{
Silica Nanoparticles as a Potential Carrier for Doxycycline Hyclate
}

\author{
M. M. Ashour(1), I. E. Soliman(2), M. Mabrouk ${ }^{(3)}$, H. H. Beherei( ${ }^{(3)}$, K. M. Tohamy(2) \\ (1) Faculty of Engineering, Badr University in Cairo (BUC), Cairo, Egypt. \\ (2) Biophysics Branch, Physics Department, Faculty of science, Al-Azhar University, \\ Nasr City, 11884, Cairo, Egypt. \\ (3) Refractories, Ceramics and Building materials Department, National Research \\ Centre, 33 El Bohouth St. (former EL Tahrir st.)- Dokki- Giza-Egypt P.O.12622.
}

\begin{abstract}
QILICA nanoparticles $\left(\mathrm{SiO}_{2} \mathrm{NPs}\right)$ have found applications in many advanced biomedical $\checkmark$ fields. This research work is concerned with the preparation of amorphous silica nanoparticles by the hydrolysis of tetraethyl orthosilicate (TEOS) in ethanol medium and different surfactants such as cetyltrimethylammonium bromide (CTAB) and polyvinylpyrrolidone (PVP) and study the final properties of the prepared silica nanoparticles. The synthesized nanoparticles were systematically characterized by XRD, FTIR, particle size analysis and TEM. The XRD results revealed the crystallinity of silica nanoparticles. FTIR spectroscopy confirmed the presence of Si-O in the sample. The data obtained from DLS showed that particles with size of $198 \mathrm{~nm}$ had prepared. Moreover, the cytotoxicity of blanked silica NPs and Doxycycline Hyclate (DOX) loaded silica NPs on Human bone osteosarcoma cells (Saos-2) was evaluated by 3-(4,5-dimethylthiazol-2-yl)-2,5-diphenyltetrazolium bromide (MTT) assay. The results approved that the fabricated Silica nano particles are biocompatible and have the potential to be a convenient drug carrier.
\end{abstract}

Keywords: Silica nanoparticles, Microemulsion synthesis, cytotoxicity, Doxycycline Hyclate.

\section{Introduction}

As of late, enthusiasm for the scientific research of silica nanoparticles has widely expanded in view of their easy fabrication and wide uses in different modern applications, for example, catalysis, pigments, drug delivery, electronic and thin film substrates, thermal encasings and humidity sensors [1]. The silica particles assume an alternate job in every one of the above applications; the nature of these items is exceptionally subject to the size and size distribution of the particles [2]. Stober et al., [3] in 1968 announced a spearheading strategy for the combination of circular and monodisperse silica nanoparticles from watery alcohol solutions of silicon alkoxides with the existence of alkali as a catalyst, and various sizes of silica nanoparticles were prepared extending from $50 \mathrm{~nm}$ to $1 \mu \mathrm{m}$ with a tight size distribution.

The size of particles relies upon the kind of silicon alkoxide and alcohol. The synthesis of nanosized silica particles from a precursor framed by trans-esterification response of tetraethoxysilane with n-decyl liquor and (aminopropyl) trimethoxysilane, with the existence of a stabilizer and an emulsifier has reported [4]. Another strategy for the preparation of silica nanoparticles utilizing oil microemulsion method to form silica nanoparticles of homogenous size circulation. Further, the size of the particles can be constrained by the sythesis of the microemulsion [5]. Preparation of silica nanoparticles utilizing tetraethylorthosilicate, water, aqueous ammonia, ethanol and octadecyltrimethoxy silane as constituents had also obtained [6]. Silica nanosphere has created utilizing heterogeneous and homogeneous systems, separately. Homogeneous system contains a blend of ethanol, water, watery alkali and tetraethylorthosilicate (TEOS). On account of heterogeneous system, just ethanol was missing [7].

In homogeneous system, sphericalsilicaparticles were combined without cetyltrimethylammonium bromide (CTAB), which gave bimodal molecule size and lower yield (77\%). To improve the yield, CTAB was included and discovered that the yield was high (100\%). The molecule was in nm extend, however the molecule sizes are bimodal. To 
maintain a strategic distance from it, response in heterogeneous system utilizing CTAB was done. Nanosized silica spheres with uniform size (yield, 94\%) was maintained. There is another technique for synthesis of silica nanoparticles by hydrolysis of silica powder has announced. As indicated by them, the solution synthesis and temperature of the response influenced the synthesis. The particles size distribution was not uniform but that was refined by facile regrowth method in a similar reaction [8]. Furthermore, a modified synthesis of silica nanoparticles by sol-gel process has been detailed whereas that, the capability to control the particle size and particle size distribution was discovered profoundly reliant on blending methods of the reactants and drying techniques. The mixture of ethanol and tetraethoxysilane followed by supplement of water delivered monodispersed powder with particle size of $10.6 \pm 1.40 \mathrm{~nm}$ with a narrow size distribution. The freeze-dryer technique further improving powder nature [9]. Amorphous and spherical silica nanoparticles with an average diameter of $25 \mathrm{~nm}$, further, temperature should be at $60{ }^{\circ} \mathrm{C}$ and the stirring speed, adjusted at $250 \mathrm{rpm}$ have prepared by sol-gel processing utilizing sodium silicate as a precursor [10].

It is also well known that, the diameter of silica nanoparticles is fundamentally influenced by the relative contribution from nucleation and growth as reported in previous study [11]. Practical data showed that the size of silica colloids diminished with increasing with tetraethyl orthosilicate and ammonia. Besides, they have examined the influence of a surfactant specifically hexamethyldisilazane on the dispersibility of silica nanoparticles.

A progression of mesoporous silica nanoparticles (MSN) with different physical properties were prepared by means of liquid crystal templating technique by differing the molar concentrations of the reagents [12]. It was confirmed that a sensitive harmony between all the reagents in the reaction mix is important so as to form nanoparticles with attractive properties. As indicated, liquid based MSN formation techniques are adaptable and hearty.

Singho and Johan, 2012, [13] fabricated silica nanoparticles by sol-gel strategy from tetraethoxysilane (TEOS), ethanol $\left(\mathrm{C}_{2} \mathrm{H}_{5} \mathrm{OH}\right)$, water and ammonium hydroxide $\left(\mathrm{NH}_{4} \mathrm{OH}\right)$ as catalyst. They referenced that the morphology and structure of colloidal silica particles shaped relied upon the molar proportion of reagents.
Complex impedance spectroscopy study indicated the existence of both bulk and grain boundary influence the material nature. Moreover, aminofunctional trialkoxysilanes, for example, aminopropyl trimethoxysilane (APTMS) and (3-trimethoxysilylpropyl) diethylenetriamine (DETAS) as surface adjustment molecule for producing monolayer alteration on the surface of silica nanoparticles had utilized [14]. They affirmed that the reactivity of amino groups on the surface-modified silica nanoparticles could be kept up in ethanol for more than 1.5 months without demonstrating any noteworthy contrasts in the reactivity.

From the above literature, obviously research endeavors are currently focused on fabricating $\mathrm{SiO}_{2}$ nanoparticles for various applications. The current work is one such exertion to prepare $\mathrm{SiO}_{2}$ nanoparticles by microemulsion technique to studying its cytotoxicity and efficiency in carrying drugs.

\section{Material and Methods}

\section{Materials}

Tetraethyl orthosilicate (TEOS) $\mathrm{C}_{8} \mathrm{H}_{20} \mathrm{O}_{4} \mathrm{Si}$ with molecular weight of $208.33 \mathrm{~g} / \mathrm{mol}$ was obtained by Merck KGaA (Germany) with surfactant Cetyltrimethylammonium bromide (CTAB) $\mathrm{C}_{19} \mathrm{H}_{42} \mathrm{BrN}$ obtained from HAS HMRZEL lab (Netherland) loss drying $2 \%$ at $100{ }^{\circ} \mathrm{C}$ as a liquid crystal templating. Ethyl alcohol absolute with Molecular Weight of $46.07 \mathrm{~g} / \mathrm{mol}$ was purchased from ADWIC (EL Nasr pharmaceutical chemicals com, Egypt) and poly (vinyl alcohol) (PVA) $\left(\mathrm{C}_{2} \mathrm{H}_{4} \mathrm{O}\right)$ n with viscosity $25-32$, degree of polymer 1700-1800 and $\mathrm{pH}$ 5-7 from LOHA CHEME (India). Cyclohexane $\mathrm{C}_{6} \mathrm{H}_{12}$, Molecular Weight $84.16 \mathrm{~g} / \mathrm{mol}$ from ALPHA CHMIKA (India).

Preparation of $\mathrm{SiO}_{2}$ nanoparticles by microemulsion technique

In this technique, two solutions (A and B) were readied, initially, solution A was acquired by dissolving of $4 \mathrm{~g}$ of PVA in of $250 \mathrm{ml} \mathrm{D.W}$ and $150 \mathrm{ml}$ ethanol during mixing at $70^{\circ} \mathrm{C}$, and this was trailed by addition of $0.8 \mathrm{~g}$ of CTAB to this solution and continued mixing till a limpid solution was gotten. Solution B, $25 \mathrm{ml}$ TEOS added to 20 $\mathrm{ml}$ cyclohexane during mixing for $30 \mathrm{~min}$ at room temperature. Moreover, solution B was drop-wised against solution A, during mixing for other $2 \mathrm{~h}$ so as to maintain the micro emulsion state. After centrifugation of the mixture, the precipitated particles were dried at $70^{\circ} \mathrm{C}$ for overnight. The sample was afterword calcined at $600^{\circ} \mathrm{C}$ for $2 \mathrm{~h}$. 


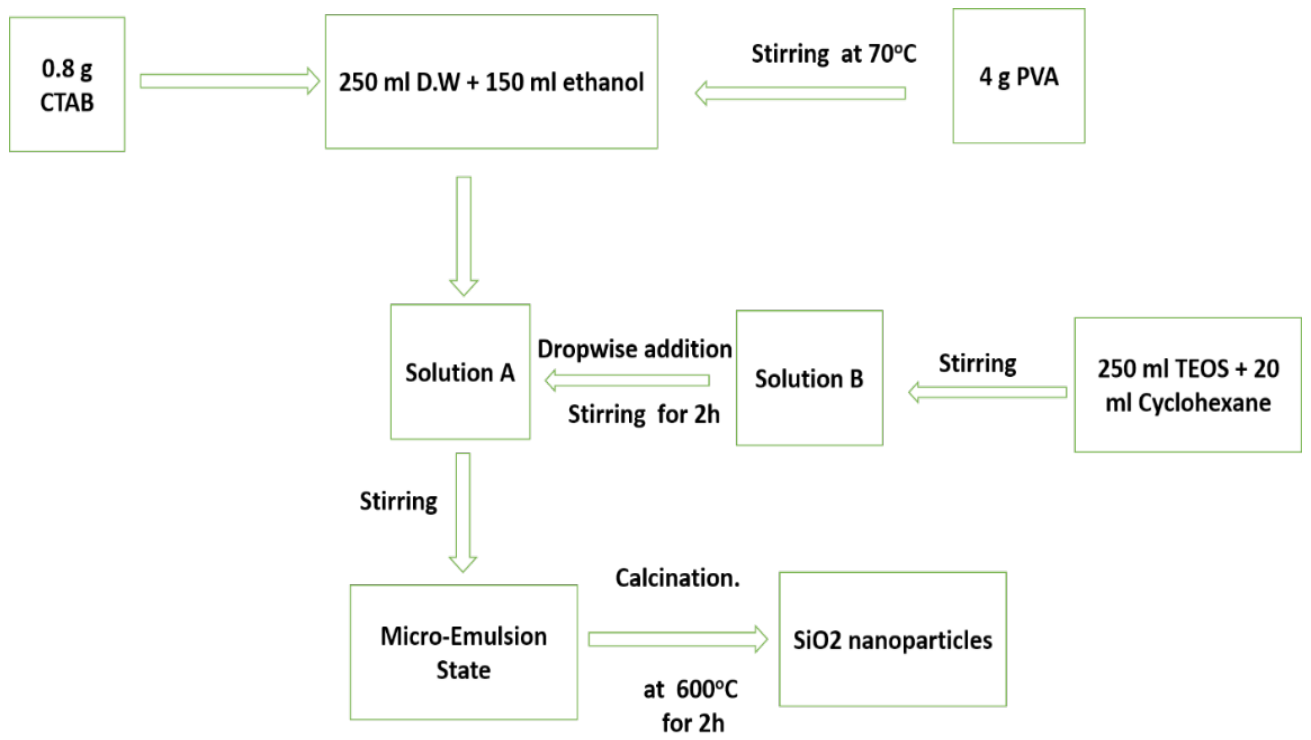

Fig.1. Preparation of $\mathrm{SiO}_{2}$ by microemulsion processing.

\section{Materials characterizations}

The microstructure, morphology and particle size distribution characteristics of the fabricated sample were investigated by Transmission Electron Microscope (TEM) and Zeta sizer (DLS). Moreover, the physico-chemical properties were maintained using XRD and FTIR analysis.

XRD measurement was evaluated by using a Diano X-ray diffractometer using $\mathrm{Cu}$ Ka radiation ( $\lambda=0.1542 \AA$ ), a tube voltage of $40 \mathrm{kV}$ and a tube current of $40 \mathrm{~mA}$ (diameter $401 \mathrm{~mm}$ ) were applied with a scintillation counter and $\mathrm{Cu}$-tube with excitation conditions of $36 \mathrm{~mA}$ and $45 \mathrm{kV}$.

FTIR curve was obtained in the range of $400-4000 \mathrm{~cm}^{-1}$ at room temperature by using Demonstrate 1600, Perkin-Elmer USA. Experimentally, a mix of prepared sample and $\mathrm{KBr}$ was compressed with a pellet through in an evacuated die and the pellet was examined by FTIR.

In addition, ZetasizerNano ZS, Malvern Instruments, UK accessorized with a $633 \mathrm{~nm}$ laser was employed to measure the particle size and surface charges. $50 \mathrm{mg}$ of sample were suspended in $10 \mathrm{ml}$ of deionized water, and filtered utilizing a $0.22 \mu \mathrm{m}$ filter beforeanalysis. A disposable capillary cell (DTS1060, Malvern) was loaded with sample prior to measurement process. Malvern instrument's dispersion technology software (Version 4.0) was used for data analysis and zeta-potential values were evaluated from the measured electrophoretic mobility data.

$200 \mathrm{KV}$ acceleration voltage Hitachi HF2000, Tokyo, Japan, Transmission Electron Microscope (TEM) has employed to investigate the morphological properties and diameter of prepared sample. Experimentally, a small amount of sample was dispersed into a mix of distilled water and ethanol (2:3). A grid of copper was submerged in the suspension for short period and dried at room temperature and the grid was settled down into the device for taking TEM image.

Drug loading and drug release behavior

$200 \mathrm{mg}$ of prepared Silica nanoparticles was added to $200 \mathrm{ml}$ of distilled water and mixed via magnetic stirrer over $30 \mathrm{~min}$ and then $200 \mathrm{mg}$ of doxycycline hyclate (DOX) was dissolved in the obtained suspension. To evaluate the in vitro drug release kinetics $200 \mathrm{mg}$ of dox-loaded silica nanoparticles had been soaked up in $200 \mathrm{ml}$ of PBS buffer solution. To analyze the amount of drug release, $10 \mathrm{ml}$ of solution was secluded at different time intervals up to 30 days then the same amount of pure PBS was involved, the concentration of released dox was investigated by UV spectrophotometer at $\lambda=273 \mathrm{~nm}$.

Cell viability

Cytotoxicity of prepared sample was evaluated against Saos- 2 cells utilizing the MTT cell practicality test. The degree of the decrease of MTT was evaluated by estimating the absorbance at $570 \mathrm{~nm}$. In subtleties, cells $(0.5 \times 105$ cells/ well), in serum free media, were put in a flat

Egypt. J. Biophys. Biomed. Eng., Vol. 20 (2019) 
bottom 96-well microplate, and treated with $20 \mu 1$ of sequential concentrations of the sample for $72 \mathrm{~h}$ at $37^{\circ} \mathrm{C}$, in a humidified $5 \% \mathrm{CO}_{2}$ air. After incubation, media were expelled and $40 \mu \mathrm{l}$ MTT arrangement $[5 \mathrm{mg} / \mathrm{ml}$ of MTT in $0.9 \% \mathrm{NaCl}] /$ well were included and incubated for extra $4 \mathrm{~h}$. MTT crystals were solubilized by including $180 \mu \mathrm{l}$ of fermented isopropanol/well and plate was shacked at room temperature, trailed by photometric determination of the absorbance at $570 \mathrm{~nm}$ utilizing microplate ELISA. Four iterate were performed for each concentration and the average was determined. Data were expressed as the percentage of relative viability compared with the untreated cells compared with the vehicle control, with cytotoxicity demonstrated by $<100 \%$ relative viability. The half-maximal inhibitory concentration $\left(\mathrm{IC}_{50}\right)$ was additionally determined from the equation of the dose response curve.

\section{Result and Discussion}

\section{$X$-ray diffraction study}

XRD pattern of the sample after calcination at $600^{\circ} \mathrm{C}$ has appeared in Fig. 2. Zhang Le-Tian et al. have arranged the $\mathrm{SiO}_{2}$ film by flame hydrolysis process and affirmed the amorphous structure of the film [15].Xiaoyi Shen et al.

.1 have arranged monodisperse circular $\mathrm{SiO}_{2}$ by microwave hydrothermal technique and they have detailed that the synthesized $\mathrm{SiO}_{2}$ particles were amorphous with no crystallization [16]. The wide XRD reflection pinnacles might be because of the little size and incomplete internal structure of the particles. Gorji et al. have arranged $\mathrm{SiO}_{2}$ nanoparticles arranged by sol-gel technique and they have announced that a high level of particles is amorphous not many of them are crystalline according to XRD information [17].

It is commendable noticed that, the sample shows a wide amorphous peak in the scope of 15 $30^{\circ}$ with greatest power at $2 \theta=23^{\circ}$. Be that as it may, little diffraction peaks at $2 \theta=30^{\circ}, 43^{\circ}$, which may be because of the existence of some leftover polluting influence from the surfactant or PVA polymer. This outcome is in acceptable concurrence with previous work, as they got some crystalline beaks in the XRD examples of silica nanoparticles arranged with various measure of $\mathrm{CTAB}$ as a surfactant [18]. On the opposite side, the existence of the broad hump is alluded to the presence of particles with little sizes and deficient internal structure. Therefore, we can say an enormous level of these particles are amorphous [19].

\section{FTIR Study}

FTIR spectroscopy was applied to examine the functional groups of the prepared sample inside the scope of $400-2200 \mathrm{~cm}^{-1}$, as appeared in Fig. 3. The predominant bands at 462,832, 1091 and $1230 \mathrm{~cm}^{-1}$ are identified with the bending and stretching vibrations of the silicon-oxygen bond, specifically, the bending vibrations of $\mathrm{Si}-\mathrm{O}$ at $~$ $462 \mathrm{~cm}^{-1}$, the symmetric extending vibrations of $\mathrm{Si}-\mathrm{O}$ at $\sim 802 \mathrm{~cm}^{-1}$, the asymmetric vibrations of Si-O-Si at $\sim 1091$ and $\sim 1230 \mathrm{~cm}^{-1}$ [20]. A main peak of PVA was observed at $1423.21 \mathrm{~cm}^{-1}$, this peak is assigned to $\mathrm{C}-\mathrm{H}$ bending vibration of $\mathrm{CH}_{2}$ [21] and this observation is in match with the $\mathrm{XRD}$ results. It can in this way be reasoned that $\mathrm{OH}$ bunches are as yet present because of water that was truly adsorbed by the sample from the air after calcination; in any case, beside this water, the calcinated tests are unadulterated $\mathrm{SiO}_{2}$. These perceptions give proof of the synthesis of silica

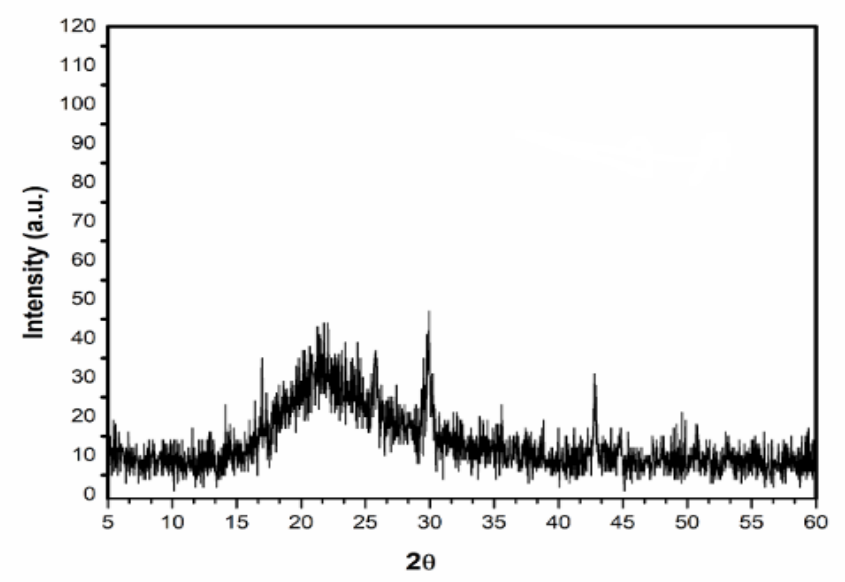

Fig. 2. XRD pattern of $\mathrm{SiO}_{2}$ powder prepared by microemulsion method. 


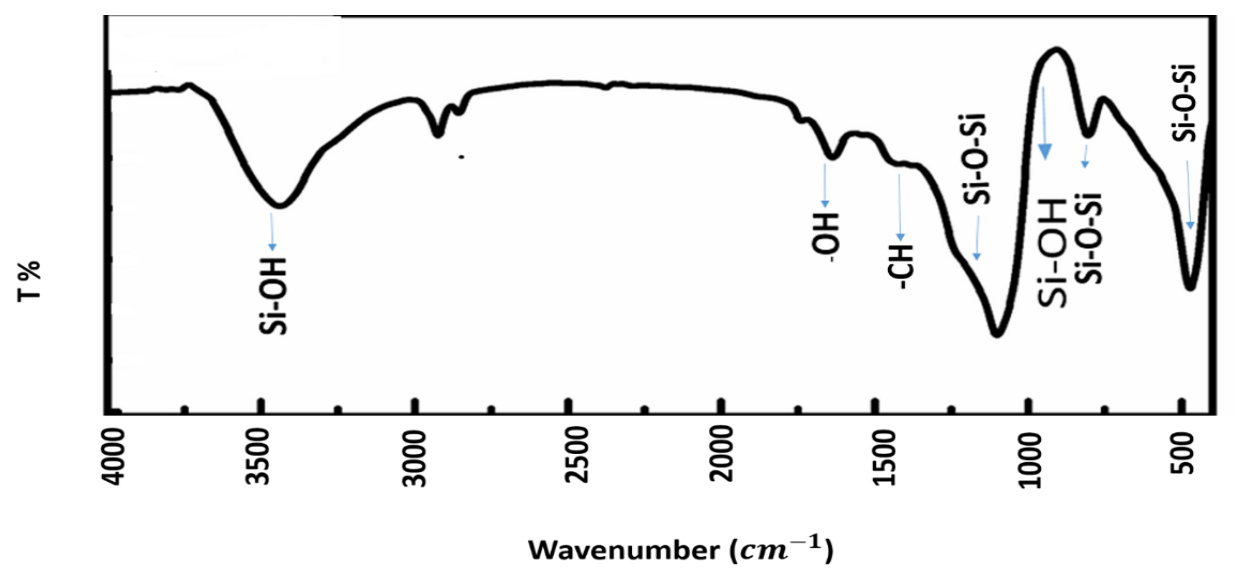

Fig. 3. FTIR spectra of $\mathrm{SiO}_{2}$ powder prepared by microemulsion method.

nanoparticles [22].

Particle size analysis

The particle size distribution curve acquired with silica nanoparticles manufactured by microemulsion technique with particle size of 198 $\mathrm{nm}$ is appeared in Fig. 4. For the estimation, 0.001 $\mathrm{g}$ of silica was sonicated in $30 \mathrm{ml}$ triple distilled water for around 10 minutes and after which the sample was oppressed for particle size investigation (DLS). The characteristics data of particles has got on silica nanoparticles is demonstrated in Table 1. The existence of large size particles (>500 nm) in the sample might be because of high temperature treatment. It was accounted for that the higher temperature will make agglomeration happen all the more promptly [23]. The zeta potential value of

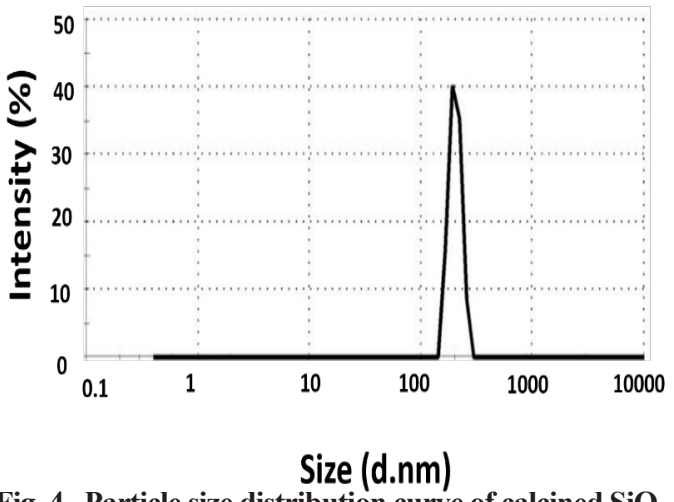

Fig. 4. Particle size distribution curve of calcined $\mathrm{SiO}_{2}$.

TABLE 1. Average particle size, PDI and Z. Potential obtained from DLS.

\begin{tabular}{|c|c|}
\hline Average particle size $(\mathrm{d} \mathrm{nm})$ & 198 \\
\hline PDI & 0.97 \\
\hline Z. Potential $(\mathrm{mV})$ & -19.9 \\
\hline
\end{tabular}

sample was evaluated to be $-19.9 \mathrm{mV}$.

TEM study

Fig. 5 shows TEM images of silica particle prepared by microemulsion techniques, based on these images, silica particles appear as irregular nanoparticles with agglomeration in shape. As mentioned before, there is a variety fit as the shape and size of the silica nanoparticles created. This variety is identified with the difference in the nucleation and growth rate of the produced silica nanoparticles with each technique of preparation utilized [24]. Concerning, particles size growth is influenced by the rate of hydrolysis and buildup response brought about by the concentration of hydroxyl gathering. In the writing [25] indicated the measure of $\mathrm{OH}$ group was impacted by the volumetric proportion of ethanol to water. The more grouping of $\mathrm{H}_{2} \mathrm{O}$ content in the reactants the more rate of hydrolysis, simultaneously, the buildup rate was diminished because of $\mathrm{H}_{2} \mathrm{O}$ arrangement [26].

In this way, particles size and particle size dissemination of silica powder were constrained by directing the amount of ethanol and water engaged with the preparation technique. Then, there are a few boundaries in this strategy that affect the final size and morphology of silica powder during arrangement by this procedure. For instance, a portion of these boundaries are $\mathrm{pH}$ estimation of the watery phase, the viscosity of the outer oil phase, type and concentration of the surfactant (cationic, ionic, and nonionic surfactants), the diameter of microemulsion droplets and (water to surfactant) molar proportion [27-29]. By these changing boundaries, the quantity of nucleation sites was controlled and in this way the size and growth rate of the subsequent silica particles was controlled [30]. Larger size particles existed in the sample might be due to agglomeration during 


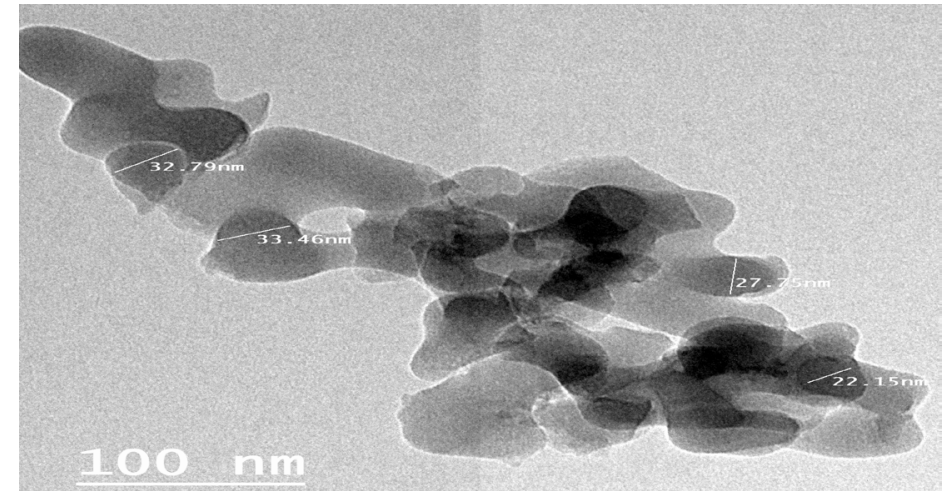

Fig. 5. TEM photograph obtained on calcined $\mathrm{SiO}_{2}$ nanoparticles prepared by microemulsion method.

treatment at high temperature $\left(600^{\circ} \mathrm{C}\right)$.

In vitro release study

The released amount of drug into the PBS buffer solution was determined by UV spectrophotometer at $273 \mathrm{~nm}$. The cumulative drug release $(\% \mathrm{CDR})$ profile of doxycycline hyclate (DOX) released from prepared sample was shown in Fig. 6. However, the profile of drug release of prepared sample exhibit prolonged burst release respectively of $90 \%$ within $\sim 170 \mathrm{~h}$, and it was growed up to $350 \mathrm{~h}$, Moreover, 55, 80 and $\sim 100 \%$ of drug were respectively released in 25,125 and $\sim 335 \mathrm{~h}$.

Cytotoxicity assay

The in vitro cytotoxicity of DOX-loaded silica NPs against Saos-2 cells was assessed by the MTT method and compared with Silica NPs at dose levels of $12,25,50$ and $100 \mu \mathrm{g} / \mathrm{mL}$. In order to confirm that the cytotoxicity of DOX-loaded silica was mainly induced by the release of DOX, not the carriers, the cytotoxicity of blank silica NPs was also studied. As shown in Fig.7 a, the silica NPs exhibited no apparent cytotoxic effect on Saos-2 cells at all test concentrations, even at the high concentration of $100 \mu \mathrm{g} / \mathrm{mL}$, the cell viability was higher than $95 \%$ indicating low toxicity and good biocompatibility. However, DOX-loaded silica NPs showed a dose-dependent cytotoxic effect against Saos-2 cells, the cytotoxicity obviously increased with the DOX concentration increasing. For example, the cell viability was decreased from $58.11 \%$ at the $12 \mu \mathrm{g} / \mathrm{mL}$ drug concentration to $39.15 \%$ at the $50 \mu \mathrm{g} / \mathrm{mL}$ drug concentration for DOX-loaded silica NPs and the $\mathrm{IC}_{50}$ value of free silica NPs is $377 \mu \mathrm{g} / \mathrm{ml}$ and $20 \mu \mathrm{g} / \mathrm{ml}$ for drug

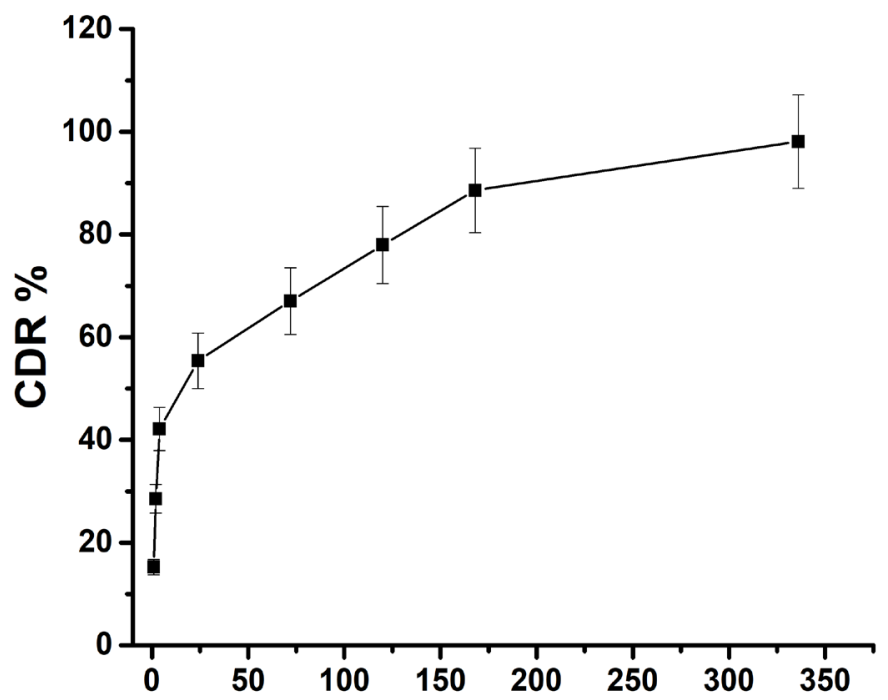

Fig. 6. The in vitro drug release of Silica NPs. 

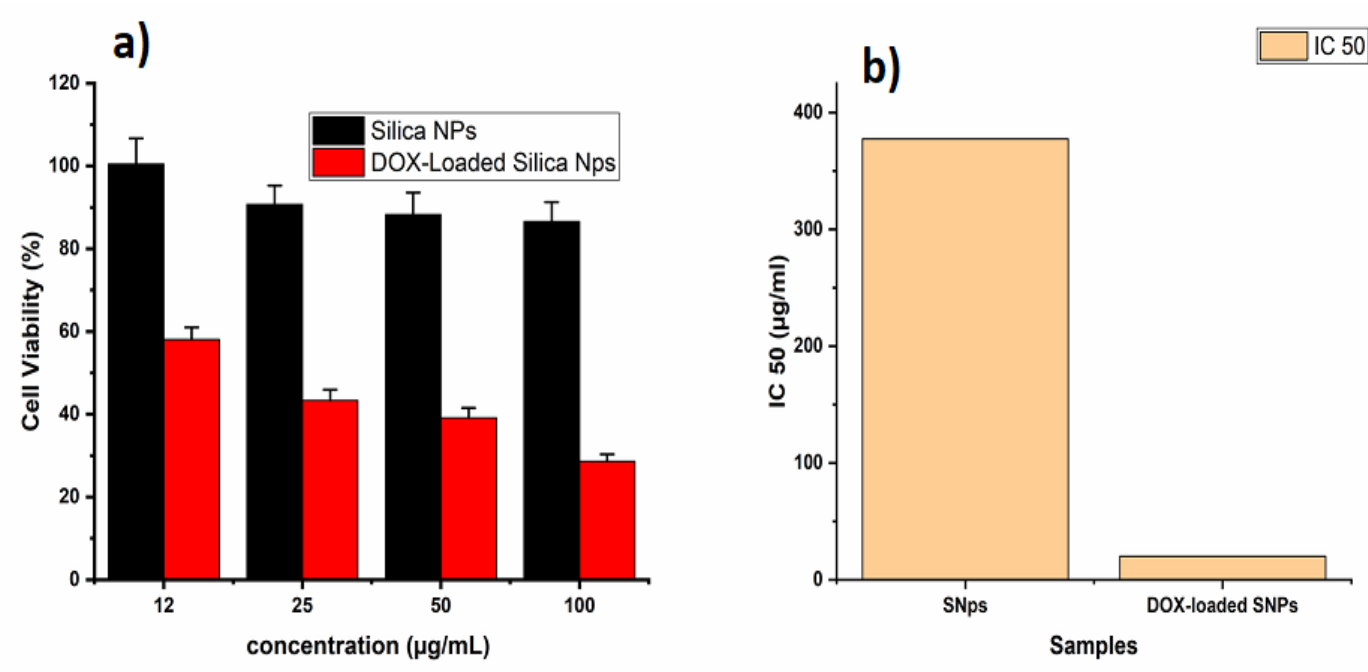

Fig. 7. In vitro cytotoxicity of a) Silica NPs and DOX-loaded Silica NPs, and b) $\mathrm{IC}_{50}$ on Saos-2 cells after $72 \mathrm{~h}$ incubation.

loaded sample.

\section{Conclusion}

Micro emulsion synthesis of $\mathrm{SiO}_{2}$ nano particles utilizing tetraethyl orthosilicate (TEOS), ethanol, water and cyclohexane with surfactants (CTAB and PVP) is obtained. The XRD data acquired on $\mathrm{SiO}_{2}$ powder shows that the sample is Simi crystalline in nature. From the FTIR analysis, it is demonstrated that the sample displayed characteristic peaks for $\mathrm{SiO}_{2}$. Also, the drug release study showed that, moderate release of drug which could be suitable for some cases of medication. The particulate properties gained on $\mathrm{SiO}_{2}$ sample indicated that the particles are existing from nanometer to micrometer size.

\section{$\underline{\text { References }}$}

1. Giesche H. Synthesis of monodispersed silica powders. II. controlled growth reaction and continuous. Journal of the European Ceramic Society., 14, 205-214 (1994).

2. Rahman IA, Padvettan V. Synthesis of silica nanoparticles by sol-gel: size-dependent properties, surface modification, and application in silica-polymer nanocomposities-a review. Journal of Nanomaterials., 1-15 (2012).

3. Stöber W, Fink A, Bohn E. Controlled growth of monodisperse Silica spheres in the micron size range. Journal of Colloid and Interface Science., 26, 62-69 (1968).

4. Chrusciel J, Slusarski L. Synthesis of nanosilica by the sol-gel method and its activity toward polymers. Materials Science., 21, 461-469 (2003).

5. Abarkan I, Doussineau T, Smaihi M. Tailored macro/micro structural properties of colloidal silica nanoparticles via microemulsion preparation. Polyhedron., 25 (8),1763-1770 (2006).

6. Venkatathri N., Preparation of silica nanoparticle through coating with octyldecyltrimethoxy silane. Indian Journal of Chemistry., 46, 1955-1958 (2007).

7. Venkatathri N., Synthesis of silica nanosphere from homogeneous and heterogeneous systems. Bulletin of Materials Science, 30, 615-617 (2007).

8. Guo JJ, Liu XH, Cheng YC, Li Y, Xu G J, Cui P. Size-controllable synthesis of monodispersed colloidal silica nanoparticles via hydrolysis of elemental silicon. Journal of Colloid and Interface Science., 326, 138-142 (2008).

9. Jafarzadeh M, Rahman IA, Sipaut CS. Synthesis of silica nanoparticles by modified sol-gel process: the effect of mixing modes of the reactants and drying techniques. Journal of Sol-Gel Science and Technology., 50, 328-336 (2009).

10. Zawrah MF, El-Kheshen AA, Haitham M, AbdEl-Aal. Facile and economic synthesis of silica nanoparticles. Journal of Ovonic Research, 5, 129-133 (2009).

11. Ibrahim,IA, Zikry AAF, Sharaf M A. Preparation of spherical silica nanoparticles: Stober silica. $J$. Am. Sci., 6, 985-989 (2010).

12. Wanyika H, Gatebe E, Kioni P, Tang Z, Gao 
Y. Synthesis and characterization of ordered mesoporous silica nanoparticles with tunable physical properties by varying molar composition of reagents. African Journal of Pharmacy and Pharmacology., 5, 2402-2410 (2011).

13. Singho ND, Johan MR. Complex impedance spectroscopy study of silica nanoparticles via sol-gel method. International Journal of Electrochemical Science., 7, 5604-5615 (2012).

14. Jung HS, Moon DS, Lee JK. Quantitative analysis and efficient surface modification of silica nanoparticles. Journal of Nanomaterials., (2012.)

15. Zhang LT, Xie WF, Wu YD, Xing H, Li AW, Zheng W, Zheng YS. Thermal annealing of $\mathrm{SiO}_{2}$ fabricated by flam hydrolysis deposition. Chinese Physics Letters., 20, 1366-1368 (2003).

16. Shen X, Zhai Y, Sun Y, Gu H. Preparation of monodisperse spherical $\mathrm{SiO}_{2}$ by microwave hydrothermal method and kinetics of dehydrated hydroxyl. Journal of Materials Science \& Technology., 26, 711-714 (2010).

17. Gorji B, Allahgholi Ghasri MR, Fazaeli R, Niksirat N. Synthesis and characterizations of silica nanoparticles by a new sol-gel method. Journal of Applied Chemical Research., 6, 22-26 (2012).

18. Stanley R, Samson Nesaraj A. Effect of Surfactants on the Wet Chemical Synthesis of Silica Nanoparticles. International Journal of Applied Science and Engineering., 12, 9-21 (2014).

19. Her YS, Lee SH, Matijević E. Continuous precipitation of monodispersed colloidal particles. II. $\mathrm{SiO}_{2}, \mathrm{Al}(\mathrm{OH})_{3}$, and $\mathrm{BaTiO}_{3}$. Journal of materials research., 11, 156-161(1996).

20. Soliman, IES, Metawa, AES., Aboelnasr, MAH, Eraba, KT. Surface treatment of sol-gel bioglass using dielectric barrier discharge plasma to enhance growth of hydroxyapatite. Korean Journal of Chemical Engineering, 35(12), 24522463 (2018).

21. Kharazmi A, Faraji N, Hussin RM, Saion E, Yunus WMM, Behzad K. Structural, optical, opto-thermal and thermal properties of $\mathrm{ZnS}$ PVA nanofluids synthesized through a radiolytic approach. Beilstein journal of nanotechnology., 6, 529-536 (2015)

22. Sadek OM, Reda SM, Al-Bilali RK. Preparation and characterization of silica and clay-silica coreshell nanoparticles using sol-gel method. Advances in Nanoparticles., 2, 165-175 (2013).

Egypt. J. Biophys. Biomed. Eng., Vol. 20 (2019)
23. Tok AIY, Boey FYC, Du SW, Wong BK. Flame spray synthesis of $\mathrm{ZrO}_{2}$ nano-particles using liquid precursors. Materials Science and Engineering: B., 130, 114-119 (2006).

24. Topuz B, Şimşek D, Çiftçioğlu M. Preparation of monodisperse silica spheres and determination of their densification behaviour. Ceramics International., 41, 43-52(2015).

25. Sato-Berrú R, Saniger JM, Flores-Flores J, Sanchez-Espíndola M. Simple method for the controlled growth of $\mathrm{SiO}_{2}$ spheres. Journal of Materials Science and Engineering. A., 3, 237 (2013).

26. Dubey RS, Rajesh YBRD, More MA. Synthesis and characterization of $\mathrm{SiO}_{2}$ nanoparticles via solgel method for industrial applications. Materials Today., 2, 3575-3579 (2015).

27. Esquena J, Tadros TF, Kostarelos K, Solans C. Preparation of narrow size distribution silica particles using microemulsions. Langmuir., 13, 6400-6406 (1997).

28. Hegde RR, Verma A, Ghosh A. Microemulsion: new insights into the ocular drug delivery. ISRN pharmaceutics., (2013).

29. Bakshi MS. How surfactants control crystal growth of nanomaterials. Crystal Growth \& Design., 16, 1104-1133 (2015).

30. Chen Q, Ge Y, Granbohm H, Hannula SP. Effect of Ethanol on Ag@ Mesoporous Silica Formation by In Situ Modified Stöber Method. Nanomaterials., 8, 362 (2018). 
جزيئات السيليكا النانوية كحامل محتمل للاوكسي سيكلين هيكلات.

محمد مصطفي ابر اهيم مصطفي عاشور (1), اسلام سليمان السيد سليمان(2), مصطفي مبروك محمد علي (3), حنان حسن بحيري

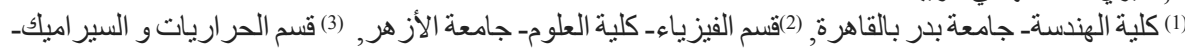

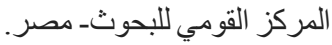

أثتبت الدر اسات أن جزيئات السيليكا النانوية (SiO NPs) يمكن استخدامها في العديد من المجالات الطبية الحيوية

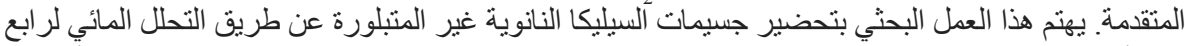

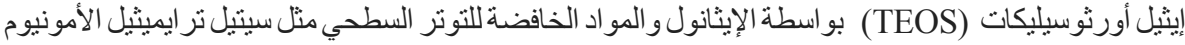
بروميد (CTAB) و البولي فينيل بيروليدون (PVP) وتمت در استة الخصائص النهائية لجسيمات السيليكا النانوية

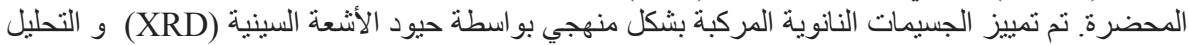

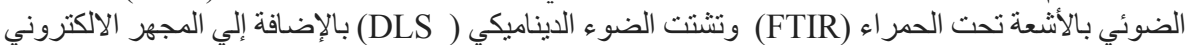

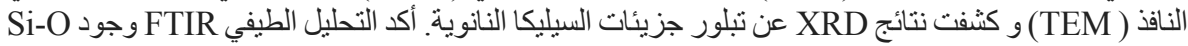

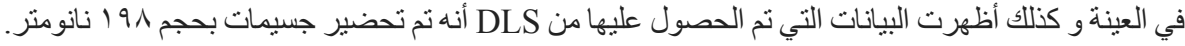

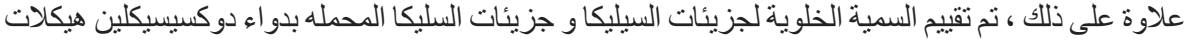

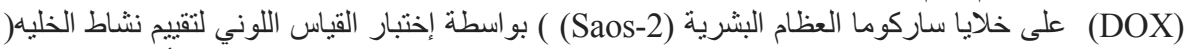
(3-(4،5-dimethylthiazol-2-yl) -2،5-diphenyltetrazolium bromide (MTT) أن جزيئات السيليكا النانوية المُصنَّعة متو افقة حيوياً ولديها القدرة على أن تكون حاملة أدوية مناسبة. 